\title{
əImproving China's Resilience to Climate-Related Risks: The China Framework for Climate Services
}

\author{
YUJIE WANG \\ Key Laboratory of Meteorological Disaster, Ministry of Education/International Joint Research Laboratory on Climate and \\ Environment Change/Collaborative Innovation Center on Forecast and Evaluation of Meteorological Disasters, and \\ School of Atmospheric Sciences, Nanjing University of Information Science and Technology, Nanjing, China \\ LIANCHUN SONG \\ National Climate Center, China Meteorological Administration, Beijing, China \\ CHRIS HEwITT \\ Met Office, Exeter, United Kingdom, and University of Southern Queensland, Toowoomba, Queensland, Australia \\ NiCOLA GOLDING \\ Met Office, Exeter, United Kingdom \\ ZILI HUANG \\ National Climate Center, China Meteorological Administration, Beijing, China
}

(Manuscript received 19 September 2019, in final form 5 May 2020)

\begin{abstract}
The primary needs for climate services in China, in the form of climate information for decision-making, are to better prepare for and manage meteorological-related disasters, adaptation to climate change, and sustainable development. In this paper, the vision, structure, content, and governance of the China Framework for Climate Services, which is designed to respond to these primary needs, is described. This paper reflects on practice, lessons, and experience developing and delivering climate services in China for disaster risk reduction, agriculture, water, energy, urbanization, and major engineering projects. Four key aspects of successful climate services are highlighted: the transition of climate research to operational climate services; delivering relevant, tailored, and usable climate information; effective engagement between users and providers of climate services; and building interdisciplinary professional teams. Key challenges and opportunities for climate services are recognized in this paper: a growing gap between climate science and services capability and societal need, a lack of awareness in user communities of the climate service value for their activities, and the important need for closer and more meaningful interactions between users and providers of climate services. The delivery and uptake of high-quality, relevant, usable, and effective climate services will facilitate climate-smart decisions that will reduce climate risks and improve Chinese societal resilience.
\end{abstract}

\section{Introduction}

The climate is of critical importance to social and economic development and human well-being. Against

D Denotes content that is immediately available upon publication as open access.

Corresponding author: Lianchun Song, songlc@cma.gov.cn the background of climate change and increasing vulnerability and exposure, society is facing unprecedented challenges in terms of climate risks (IPCC 2014). To manage and reduce climate risks as well as improve societal resilience, the World Meteorological Organization initiated the Global Framework for Climate Services in 2009 (Hewitt et al. 2012). In recent years, climate services have received considerable attention (Lourenço et al. 2016; Brasseur and Gallardo 2016; Vaughan et al. 2018). 
TABLE 1. Examples of requirements for climate services in China.

\begin{tabular}{|c|c|}
\hline Domain & Climate information \\
\hline Disaster risk management & $\begin{array}{l}\text { Climate information for the coming months, years, and decades (known as seamless } \\
\text { climate prediction) } \\
\text { Assessment of impacts of extreme weather and climate events } \\
\text { Vulnerability assessment } \\
\text { Meteorological disaster outlook and warning } \\
\text { Climate information for disaster recovery and reconstruction }\end{array}$ \\
\hline Adapting to climate change & $\begin{array}{l}\text { Monitoring and detection of climate change } \\
\text { Projections of future climate } \\
\text { Impacts of future changes in climate } \\
\text { Climate-resilient infrastructure (such as cities and transport networks) } \\
\text { Monitoring and assessment of greenhouse gas emission reductions } \\
\text { Clean energy development and utilization }\end{array}$ \\
\hline Efforts on sustainable development & $\begin{array}{l}\text { Monitoring and assessment of ecosystems } \\
\text { Assessment and monthly prediction of air quality } \\
\text { Climate information for regionally coordinated development } \\
\text { Climate information for urbanization } \\
\text { Climate resources for ecological economy }\end{array}$ \\
\hline
\end{tabular}

China suffers from a wide range of meteorological disasters, such as floods, droughts, typhoons, heat waves, frosts, haze, and sandstorms. Many of these disasters have become more frequent and result in more significant impacts on socioeconomic development in China in recent decades, and in part, these events can be attributed to climate change (see, e.g., Dong et al. 2016; Sun et al. 2016; Burke and Stott 2017; Li et al. 2018; J. Wang et al. 2018; Y. Wang et al. 2018; Chen et al. 2019).

The use of climate information in decision-making can improve society's understanding and perception of, and preparedness for, climate-related hazards; improve economic outcomes; and promote sustainable development as part of China's active pursuit of social and environmental reforms toward a more sustainable society in response to climate-related challenges-a so-called ecological civilization guiding people to a more sustainable and harmonious development path (W. Zhang et al. 2011). The key to realizing such improvements is strengthening the engagement between users and providers of climate services, as well as scientific developments supporting climate services, and better utilization of climate information (Asrar et al. 2012; Kruk et al. 2017; Weichselgartner and Artheimer 2019). China has made significant efforts to develop and advance the China Framework for Climate Services (CFCS) as a national framework to improve decision-making for social and economic benefits, drawing on and further developing scientific knowledge and capability in China and worldwide.

In section 2, we describe the current primary needs for climate services in China and introduce the CFCS designed to respond to these needs. In section 3 , the practices and experiences of delivering and using climate services to improve societal resilience to climate-related risks in China are described. In section 4, the key challenges in developing tailored climate services for the government, economic sectors, and society are highlighted to aid in better-informed decisions and policies.

\section{The China Framework for Climate Services}

\section{a. Requirements of climate services}

As stated above, to better serve society's needs in terms of coping with a changing climate, there is a growing need to improve our understanding of how the climate has varied in the past and how it could change in the future. Many of society's most pressing needs are to be able to better prepare for and manage meteorological disasters, adapt to a changing climate, and ensure that economic development is environmentally sustainable. Climate services in China are being developed to meet these pressing needs, along with a framework to enable and coordinate such activities. Table 1 highlights some of the key requirements for climate services in China, which are aligned with each of these areas, and we discuss these requirements in more detail below.

First, China is a country that has been and continues to be severely affected by meteorological disasters. From 1984 to 2018, the average annual direct economic loss caused by meteorological disasters reached 207 billion Chinese yuan ( $\$ 29$ billion), accounting for $1.8 \%$ of the gross domestic product (GDP) coupled with a death toll of up to 3710 people (Fig. 1; CMA 2017). The rapid economic and social development and urbanization in China, undertaken against the backdrop of a warming climate, has the potential to increase China's vulnerability to extreme weather and climate events such as 

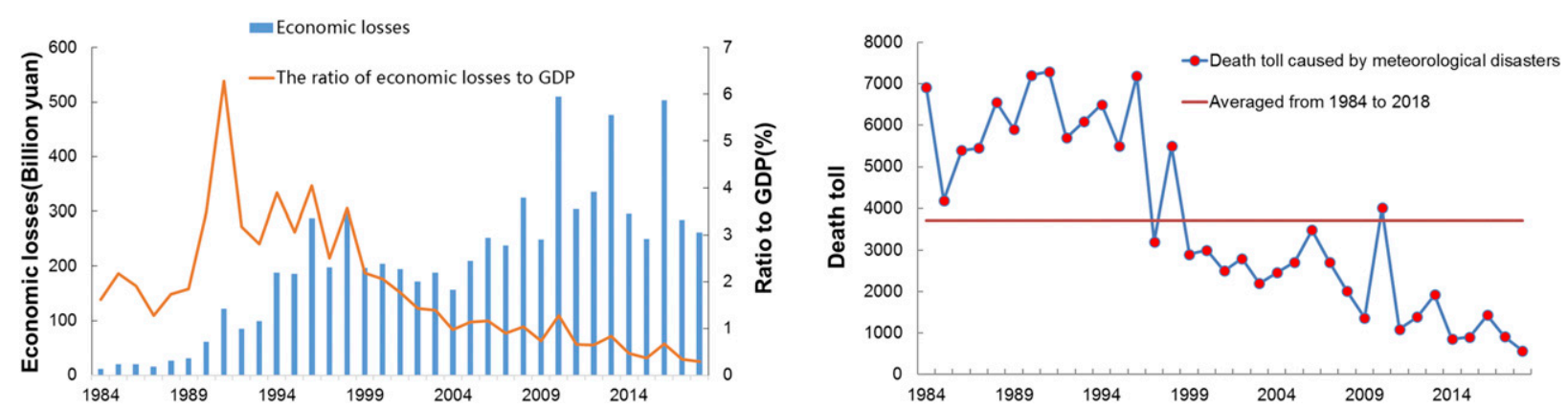

FIG. 1. The (left) economic loss and (right) death toll caused by meteorological disasters in China from 1984 to 2018.

high temperature, drought, heavy precipitation, and typhoons (Qin et al. 2015; Wang et al. 2016). Climate information is also needed to help avoid or mitigate the possible impacts of meteorological disasters on planning implementation. Therefore, it is of major national importance to provide high-quality, useful, and actionable climate services to help manage and reduce the risk of meteorological disasters, as well as to aid in sustainable development. Climate information products based on climate observations, monthly and seasonal climate predictions, and climate change projections are needed to support planning and development.

Second, mitigating and adapting to climate change while striving for economic and social sustainability poses a major challenge in China, especially for creating a low-carbon economy. Major engineering projects need to be implemented to adapt to the future climate using tailored climate information. In recent years, the ratio of people living in urban areas has rapidly grown and is expected to reach approximately $70 \%$ by 2030 in China. With the Paris Agreement in 2015 (UNFCCC 2015), the need for climate services to mitigate climate change became urgent in Chinese cities (Zhai et al. 2018). Climate information should scientifically and efficiently support national and local actions for climate change adaptation and mitigation, such as "low-carbon cities" (low-carbon city refers to the economic production of low carbon and low carbonization from social life to effectively improve the ecological environment of the city) ( $\mathrm{Li}$ and Zhao 2014), "sponge cities" (sponge cities are designed to tackle urban surface-water flooding and related urban water management issues) (Chan et al. 2018), and "climate-adaptive cities" (climate-adaptive city refers to a city that can effectively cope with severe weather and climate events through urban planning, construction and management) (Xie and Zheng 2017). Furthermore, China is currently the largest emitter of greenhouse gases and faces great pressures to accelerate the transition to a low-carbon energy supply in terms of climate change mitigation actions (Zhai et al. 2018).
Climate information should be used, for example, to assess potential wind and solar energies to meet future lowcarbon energy needs.

Third, climate change has exerted significant pressures on natural ecosystems that are directly relevant to future sustainable development in China (Fang et al. 2018). China's active pursuit of social and environmental reforms toward a more sustainable society in response to climate-related challenges, a so-called eco-civilization, requires new climate services. This concept of an ecocivilization involves undertaking major projects to protect and restore key ecosystems, construct National Key Ecological Function Zones (Zhai et al. 2016), and develop an ecological economy. Note: an ecological economy is a sustainable form of economy that integrates economic development and environmental protection, drawing on the potential of the available resources while ensuring ecosystems are sustainable (Zhou and Zou 2016). Climate services are needed to monitor and assess the impacts of climate variability and climate change on grassland, farmland, wetland, forest, and other important ecosystems to support policy makers in carrying out ecological environmental governance. Efforts to address desertification, environmental pollution, and soil erosion also rely on climate information. For instance, the significant regional coordinated developments taking place in the Beijing-Tianjin-Hebei region, Guangdong-Hong Kong-Macao Greater Bay Area, Yangtze River Delta, and Xiongan New Area must assess ecological vulnerability, project future climate risks, and formulate adaptive approaches to climate change to improve the resilience of these areas and pursue environmentally friendly developments.

\section{b. The vision and goals of the CFCS}

Climate service refers to the process of generating, providing, and using climate information in such a way as to assist in decision-making (Hewitt et al. 2012). The CFCS vision is to help better manage climate risks and opportunities arising from climate variability and climate 

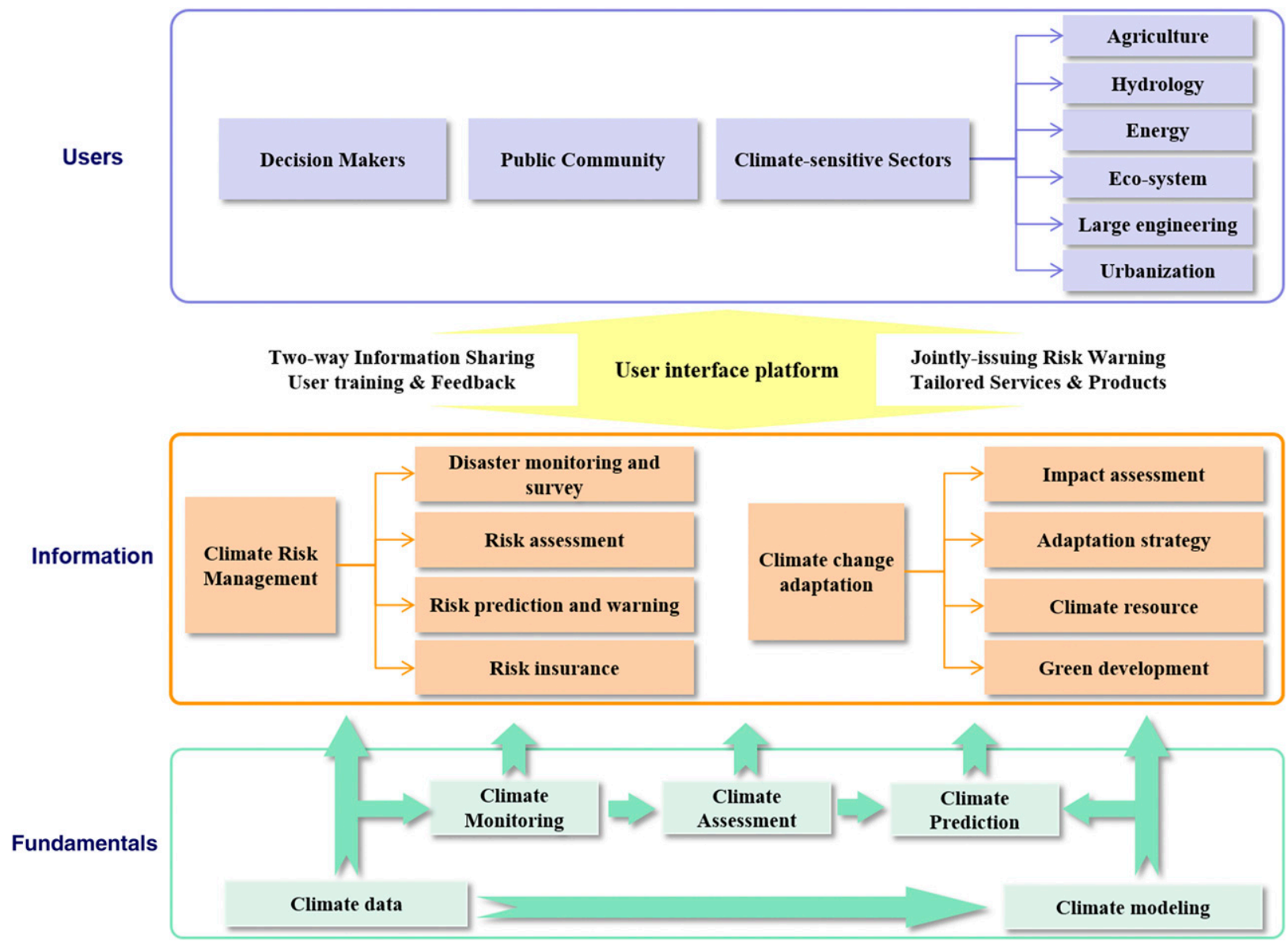

FIG. 2. The Chinese Framework for Climate Services.

change and improve societal resilience to climate-related risks through better development and the provision and use of relevant, tailored, and usable climate services in China. Specifically, CFCS aims to achieve the following goals:

- provide timely, accurate, and tailored climate services for the safety and well-being of the people,

- reduce the vulnerability of society to climate-related risks through better provision and use of climate information,

- develop partnerships between providers and users of climate services and help users better understand and benefit from climate services, and

- extend climate service areas to help society plan for and adapt to climate variability and climate change and improve societal resilience.

\section{c. Structure of the CFCS}

The CFCS is based on a foundation of climate knowledge (including from climate observations and climate models), and CFCS is supported by climate monitoring, prediction, and assessment products for disaster risk management, climate change adaptation, and mitigation. At the core of the framework is engagement between climate service providers and users to promote mutual understanding. It includes CFCS steering committees, interagency working groups, internship programs, faceto-face discussions, workshops, and joint climate prediction consultations. The CFCS provides the nation's organization and environment for developing, delivering, and using climate services in decision-making, as well as for the general public and climate-sensitive industries. Training for climate service users is important to the successful implementation of the framework and its evolution, along with feedback from service users and an ongoing assessment of the needs of users (Fig. 2).

The oldest foundation of Chinese climate services is the meteorological observation network and system. China has a real-time, three-dimensional climate monitoring system, including 2423 state climate stations and 55680 automatic weather stations, and has accumulated a wealth of historical climate data. Users can readily obtain historical and real-time climate observations, as 
TABLE 2. Regular climate service products in China.

\begin{tabular}{cl}
\hline \hline Climate service & \multicolumn{1}{c}{ Climate product } \\
\hline Climate monitoring & Climate monitoring products \\
Extreme weather and climate events & Meteorological drought monitoring products \\
Asian monsoon monitoring & El Niño-Southern Oscillation (ENSO) monitoring \\
Climate prediction & Asian monsoon prediction \\
& ENSO prediction \\
& Rainy season prediction \\
& Drought and flood outlook \\
& Tropical cyclone prediction \\
& Prediction of forest fire danger weather ratings \\
& Prediction of spring dust/sandstorms \\
Climate assessment & Prediction of first frost date \\
& Monthly high-impact weather event predictions \\
& Annual China Climate Bulletin \\
& Yearbook of Meteorological Disasters in China \\
& Annual Climate Change Monitoring Bulletin of China \\
& Annual Report on Actions to Address Climate Change \\
& Monthly National Climate Impact Assessment \\
& Climate Impact Assessment Express Monthly \\
& Atmospheric Environmental Carrying Capacity \\
& Special Report of Extreme Climate Events \\
\hline
\end{tabular}

well as outputs from climate models covering historical and future periods, to monitor and assess extreme weather and climate events. China has also established a database of hazards covering 28 meteorological disasters, including droughts, rainstorms, floods, typhoons, and so on (Zheng et al. 2019). Chinese scientists have studied the disaster thresholds of rainstorms, floods, and droughts to help society manage and reduce the risks due to meteorological disasters (Jiao et al. 2015).

Climate service products are defined within the CFCS as processed climate information and knowledge formed by integrating multidisciplinary knowledge to meet various societal needs. The most common climate service products in China include climate monitoring, climate prediction, and climate assessments (Table 2). Climate monitoring products provide information on historical changes in the climate system, a crucial component of climate services, to help establish a baseline for future changes. Some users are only concerned with weather and climate events that have occurred or are observed to be happening now and apply such information to daily decision-making. Climate prediction products use predictions for the coming months, seasons, and years to predict long-lived meteorological disasters such as drought, floods, heat waves, and cold snaps; the statistics of high-impact extreme weather events, such as the number of typhoons across a season; or special predictions for industries such as energy production or crop yield. Climate assessment products provide information about the climate impact on agriculture, energy, water resources, and human health based on current and future climates. For example, assessments of climate impact on agriculture include assessments of crop growth, impacts of agrometeorological disasters, agroclimatic resource surveys, and impacts of climate change on food security (https://www.ncccma.net/cn/).

The CFCS has developed a strong user interface platform to facilitate effective interactions among providers, researchers, and users of climate services for the development, delivery and use of climate services. For example, each year, the National Climate Center (NCC) of the China Meteorological Administration (CMA) organizes a national stakeholder consultation workshop on climate services to build dialog between climate service users and providers. Every month, the NCC invites key users to take part in climate prediction consultations to coproduce and coissue climate prediction and transform climate information into client-tailored climate services. The annual Forum on Regional Climate Monitoring-Assessment-Prediction for Regional Association II (FOCRAII) initiated in 2005 by the NCC invites scientific experts and Asian users together to produce summer climate predictions. Fifteen sessions of FOCRAII have been held since then and have provided opportunities for communications between the producers and end users of climate products to help end users obtain a better understanding and make better use of the predictions. For example, as the strong El Niño event in the summer of 2016 likely created severe flooding of the Yangtze River, the NCC invited key users such as the 


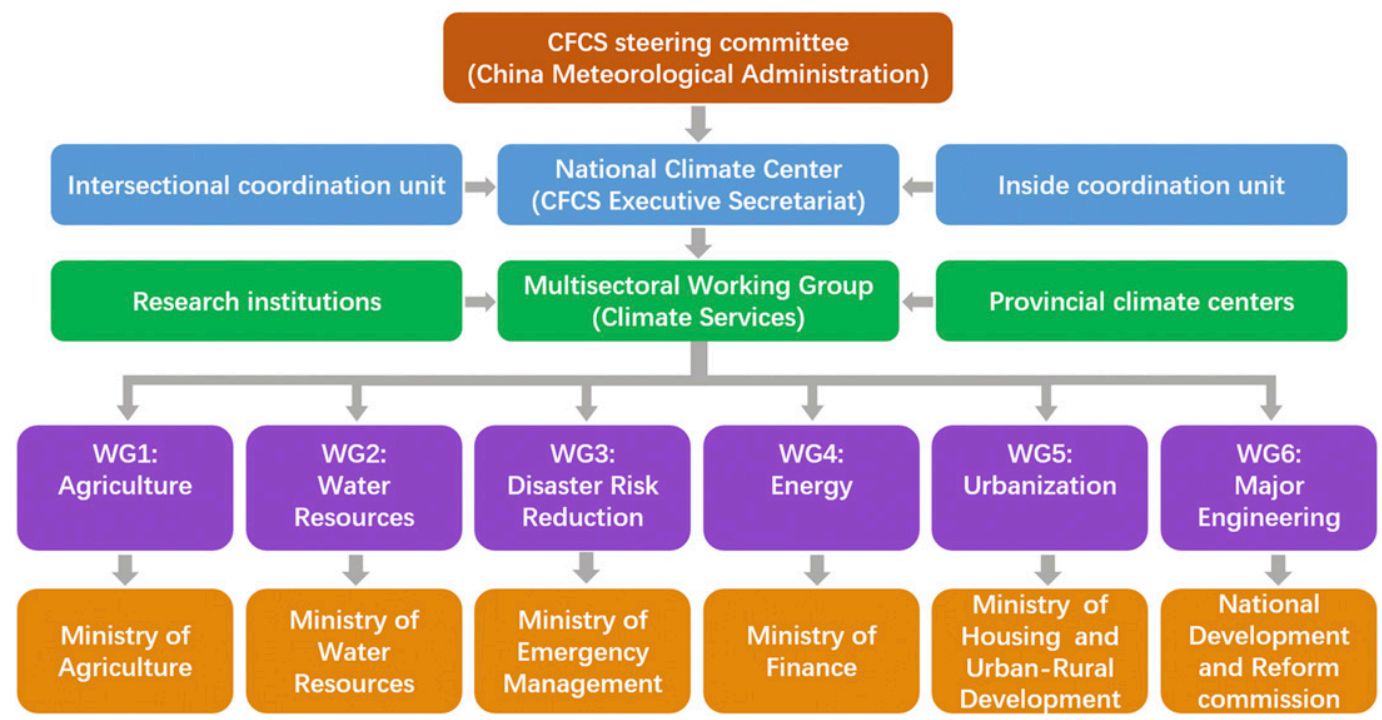

FIG. 3. The CFCS governance structure (WG: working group).

China Three Gorges Corporation and Hanjiang Group to take part in the 12th FOCRAII in April 2016. This meeting provided valuable opportunities to discuss the prediction, its interpretation, and implications between providers and users. In particular, the predictions for 2016 were compared with the severe flooding events of the Yangtze River in 1983 and 1998, which were associated with strong El Niño events. Through attendance at the FOCRAII meeting and the presence of domestic and international experts, users gained greater trust and confidence in the predictions, which greatly aids them in taking more effective measures for river management to more successfully operate the Three Gorges Dam (as an example, see Golding et al. 2019). Furthermore, outreach is very important for improving a user's climate awareness through user training; for example, each year, the NCC organizes training courses in disaster reduction for city officials and uses these courses to bring together key stakeholders to obtain feedback from user communities. To raise climate change awareness, the NCC communicates climate change knowledge with policy makers and the public through the meetings of the IPCC report team, World Meteorological Day theme activities, climate change knowledge window of newspapers, websites, and WeChat (Wang et al. 2016).

\section{d. Governance of the CFCS}

The CFCS Steering Committee (SC) was set up at the CMA at the interministerial level, which is appropriate for its national circumstances and requirements for climate services (Fig. 3). The SC is responsible for formulating a national strategic plan and implementation plan of the CFCS, determining pilot projects to meet national needs, and evaluating the benefits and problems resulting from the CFCS. The NCC of CMA is responsible for the CFCS SC Secretariat, the communication among relevant national institutions, provincial climate centers, and intersectional coordination. Six interdisciplinary working groups on agriculture, water resources, disaster risk reduction, energy, urbanization, and major engineering were established to facilitate in-depth and regular interactions among providers and users. The CFCS governance structure brings together all relevant national participants to work together to improve climate service delivery at the national scale.

\section{Practices}

The success of a climate service can be improved by integrating climate science with other relevant disciplines and joint efforts by climate scientists and users to produce knowledge together. Before taking actions, users need to reach out to climate service providers to better understand the usability and uncertainty of the climate information with which they have been provided. Different information can be used to support various decision-making processes. For instance, agricultural authorities will take preventive and reduction measures against meteorological disasters according to climate predictions at extended range and monthly to seasonal time scales (Zheng et al. 2019). Projections on climate change will be used by authorities on urban planning and construction of major projects to build the capacity to adapt to future climate changes.

In the next subsection, we describe a series of examples of climate services currently being provided in 


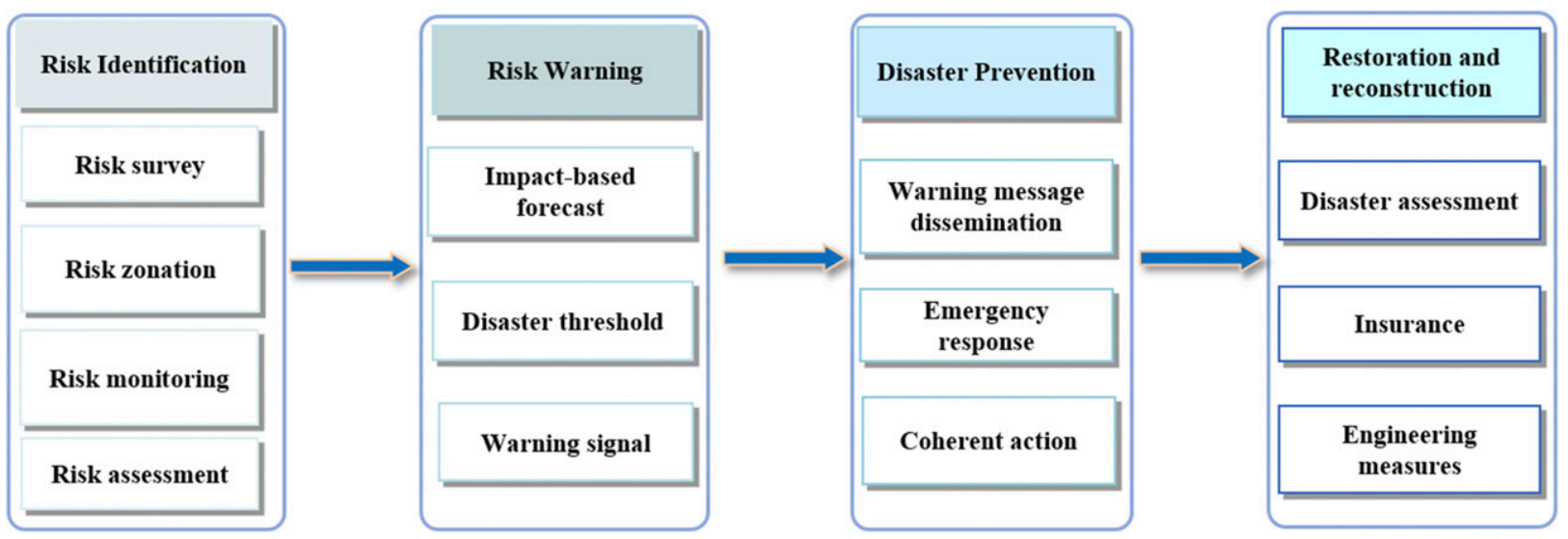

FIG. 4. The flowchart of disaster risk management in China.

China. These case studies are selected to illustrate the approach taken and the nature of climate service requirements and delivery in China.

\section{a. Climate services for disaster risk reduction}

Climate services for disaster risk reduction are the top priority at both the national and local levels in China. The whole cycle of disaster risk management includes risk identification, risk warning, disaster prevention, restoration, and reconstruction (Fig. 4). Identifying, monitoring, and assessing the risks associated with meteorological hazards are fundamental for effective disaster risk management. To identify levels of risk, the CMA, along with other government agencies, conducted risk surveys in 2012 that were placed into a database of meteorological disasters (Jiao et al. 2015). The database covers 28 different types of disasters from 1984 to 2012 in each county of China, including the factors leading to disasters, environmental hazards, disaster prevention and reduction capabilities, and disaster loss information for different economic sectors. Then, the spatial distribution of each hazard is mapped, and this information is used to identify thresholds or limits at which there is a high probability of hazard occurrence. For example, data on past fluvial flooding in an area can be used to assess probable damage before the disaster and to issue warnings for hazard prevention, reduction, and emergency response.

China has established mechanisms through government leadership, coordination among different sectors, and participation from key communities to more effectively manage disasters. Central and local governments organize meteorological disaster prevention and reduction actions and provide funding for infrastructure and disaster relief based on disaster risk monitoring and assessment. A disaster risk reduction plan ensures a multisector emergency response and interaction in terms of meteorological disaster warnings. At the community level, emphasis is placed on involving the community, key nongovernmental organizations, and volunteers, as well as improving training and transfer of knowledge to the public.

In addition to short-term risk management, the NCC has assessed the combined effects of climate change and increasing vulnerability and exposure to hazardous conditions in China based on climate change projections. Such climate services assist in building long-term resilience through restoration and reconstruction, which focus on reducing the underlying risk factors, siting critical infrastructure, transferring risks, and strengthening disaster preparedness capacity. For example, extreme heat events and extreme precipitation were projected to increase in most of the Beijing-TianjinHebei region by the end of this century (Han et al. 2019). Such climate information would provide valuable scientific support for policy makers creating climate change mitigation and adaptation strategies for the coordinated development of this region.

\section{b. Climate services for agriculture}

Accessible and usable climate information can support agricultural decision-makers who want to improve their understanding of the mechanisms of climate impacts on agricultural development and food systems (Tonya et al. 2018; Prokopy et al. 2017). In China, climate information is currently used to support food security and agriculture adaptive strategies for the central and local governments. Climate services for predicting productivity, certifying the quality of agricultural products, and agriculture insurance and trading are provided to agriculture departments, consulting firms, farmers, the insurance industry, and futures trading companies (Fig. 5).

As an example, precipitation in northern China during summer 2014 was $20 \%-50 \%$ less than normal, and severe drought occurred in the Liaoning, Jilin, Inner 


\section{Services}

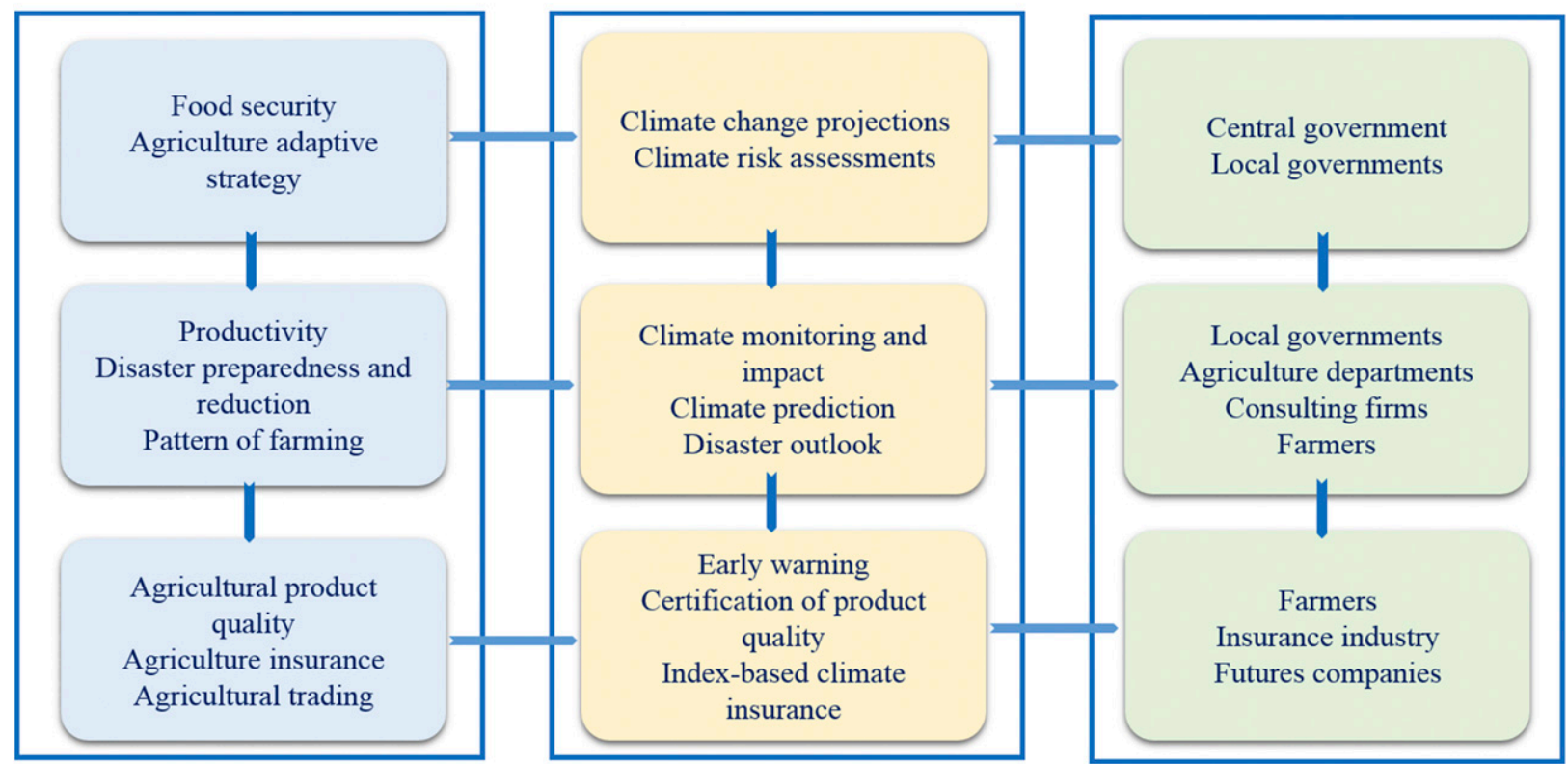

FIG. 5. The chain of climate services for agriculture in China.

Mongolia, Hebei, Shandong, and Henan Provinces. The NCC monitored drought development, including the severity, duration, and areal extent of the drought, assessed the drought risk on agriculture and water resources in real time, released drought predictions every 5 days, and jointly issued an early warning from agricultural departments to farmers. In particular, the NCC issued the red warning signal of the drought, which would be aggravated in the Henan and Liaoning Provinces in late July of this year. It reminded the local government and farmers to strengthen drought prevention and drought relief measures, such as irrigation and artificial weather modification. Due to this proactive monitoring and prediction, timely warning, and effective drought relief measures, the direct economic loss was reduced despite the large affected population of 62.2 million and the droughtaffected area of 9.9 million hectares (CMA 2015). Another example is the prediction of first frost days, which has a great impact on rice yield in Northeast China. The agricultural department uses the prediction of the date of the first frost to mitigate adverse effects and improve the chances of obtaining a good harvest.

While most impacts of a changing climate are harmful (Xiao et al. 2006), warmer conditions can offer opportunities in some regions, and careful communication of how the climatic conditions are changing can offer some benefits to decision-makers. For example, agricultural authorities have adjusted the crop layout in China, in accordance with reports submitted by the NCC regarding the impact of climate change on agricultural production. Double cropping rice, for instance, used to be grown south of the Yangtze River. Now, the presence of this rice has been expanded to north of the river. In 2010, Shangcheng County of Xinyang city, Henan Province, succeeded in growing double cropping rice, with an average yield reaching over $500 \mathrm{~kg}$ per $m u\left(666.7 \mathrm{~m}^{2}\right)$.

Agricultural decision-makers can also benefit greatly from tailored climate services such as certification of agricultural product quality and agricultural insurance. In China, there is a certification of agricultural product quality arising from favorable climatic factors. This certification helps with market competitiveness and ultimately farmer income. In addition, through certification, key factors affecting agricultural products are clearly defined, and farmers can be guided to make use of climate information for planting and improve the quality of agricultural products. For example, white tea is the main tea variety in the Zhejiang Province, and its quality is closely linked to climatic conditions. In 2013, farmers in Anji County, Zhejiang Province, achieved certification associated with good climate conditions, and the value of tea increased by $10 \%$, with 30 million Chinese yuan ( $\$ 4$ million) accumulated over a period of three years.

Index-based climate insurance is provided to the agricultural insurance industry, indexing the damage caused by climate-related factors. Each index has its 
corresponding profit and loss, and the insurance contract is based on the index. Climate services cover the research and development of index-based climate insurance products, the formulation of probabilities, climate predictions and weather forecasts, live monitoring, and confirmation of insurance claims. For example, the Fujian Meteorological Bureau has developed a low temperature meteorological index insurance product for tea, and the compensation ratio of the product is determined by the number of days that the daily minimum temperature is less than or equal to $-1^{\circ} \mathrm{C}$ from 20 days before tea picking to 6 days after tea picking. The insurance index is widely welcomed by tea farmers and the government to effectively mitigate the risk of meteorological disasters (Zheng et al. 2019).

\section{c. Climate services for the water sector}

The water sector is facing a mounting challenge in terms of building resilience to climate variability and climate change (Kirchhoff 2013). The typical monsoon climate, which is experienced across much of China, determines the uneven temporal and spatial distribution of water resources. As a result, water resources in China need to be actively managed for daily, monthly, seasonal, annual, and even decadal activities to resolve this uneven distribution for a range of uses, such as agriculture, industry, ecosystem, and domestic use (Cheng et al. 2006). The water sector receives considerable benefits through climate services in long-term strategic planning, the assessment of water availability and risks, effective water diversion, and distribution on all time scales in China.

Climate services are essential to reservoir management, especially from the flooding season to the storage period. A late storage period may result in inadequate water storage, while an early storage period may cause flood risk. In the second half of 2017, the Three Gorges Control Center started to retain water 10 days earlier than usual, based on extended-range forecasts. As a result, the water level had reached $175 \mathrm{~m}$ by 21 October. It was the quickest and earliest water storage for the Three Gorges since it began to retain water and represents a significant benefit for water resource management and electricity generation.

Carrying out interbasin water diversion to move water from regions with an excess of water to regions lacking in water requires forecasting any changes in water resources in both the water source and water receiving areas on monthly, seasonal, and annual bases. The South-to-North Water Diversion Project is a significant infrastructure project that aims to relocate water resources from areas with sufficient or too much water (largely southern China) to areas lacking water resources (primarily in northern China). Taking the Central Line of the South-to-North Water Diversion Project as an example, the runoff of the water source area and the water receiving area are both determined by the balance of too much and too little water due to climate variability. Water availability from the upper reaches of the Danjiangkou Reservoir in the source area is highly uncertain, and this significantly impacts the scheduling of water transfers from the source area to the receiving area. The NCC provided customized climate predictions at monthly, seasonal, annual and decadal time scales to the Hanjiang Group based on its specific needs, helped improve the use of climate information through training and communication, and assessed the benefits from the Hanjiang Group (Fig. 6). To formulate a water diversion plan for the next year, the NCC provided annual climate predictions for the Hanjiang Group before 20 September. In particular, summer and autumn precipitation predictions can help the Hanjiang Group to control flooding and determine reservoir storage timing and volume. The Hanjiang Group also used monthly precipitation forecasts to schedule monthly water resources. In addition, by downscaling global climate projections to a regional scale, the runoff of the water source area in the next 2030 years has become an important input for construction of the Project of Water Diversion from the Yangtze River to the Hanjiang River. However, for lead times of the next 20-30 years, the dominant contribution is natural variability (Hawkins and Sutton 2009). Therefore, it is necessary for climate communities to reduce the uncertainty of decadal climate prediction based on robust regional climate modeling efforts.

\section{d. Climate services for the energy sector}

The energy sector has a large and varied need for and use of climate predictions to estimate the energy demands of heating and cooling. Climate information is also used to assess wind and solar energy distributions to meet future energy needs. Other examples include helping to make decisions on where to site wind and solar energy facilities, assessing climate risks and warnings to support energy scheduling and safe operation for winter heating and energy production and transmission for efficient operation of air conditioning during summer as well as electricity transmissions across China's vast energy grid.

As a specific example, the Beijing Municipal City Planning and Appearance Management Committee, Beijing Municipal Finance Bureau, and Beijing Meteorological Bureau jointly hold a winter heating climate symposium and determine the likely start and end dates of the heating supply according to the results of long-term, 
Climate products, Customized service, User training

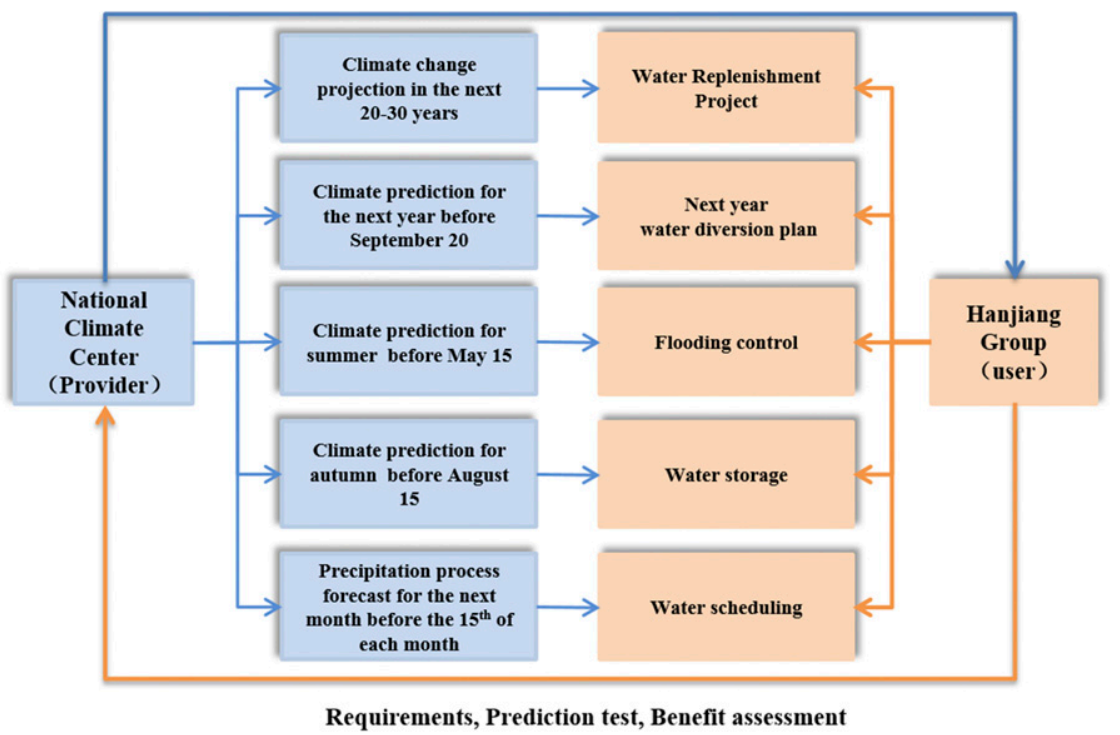

FIG. 6. Danjiangkou Reservoir Water Diversion Project climate service process.

medium-term, and short-term climate predictions as well as the meteorological standards on the start and end dates of the heating supply. Since such climate services have been used to guide heating, the Beijing District Heating Group has reduced coal consumption by $89508 \mathrm{t}$ each year, with a reduction in expenditures ranging from $3 \%$ to $5 \%$, contributing to energy savings and emissions reduction, ensuring heating quality, and protecting the environment.

The NCC has developed a dataset on the solar power resources of counties across the nation, which serves as the basis for the Poverty Alleviation Office of the State Council to carry out its photovoltaic poverty relief program. Program investments and benefit analyses are calculated based on the dataset. To mitigate climate change and promote green development, the Chinese government has accelerated the development of decentralized wind power and offshore wind power. The NCC has combined numerical model output with historical meteorological observations to develop a wind energy resource dataset with an hourly resolution from 1995 to 2017. Based on the dataset, the NCC has developed a Climate Application Platform (CLAP). This provides an important basis for national decisions on energy development planning and carbon dioxide emission reductions.

The CLAP enables energy producers and providers, electricity network managers, and policy makers to improve renewable energy integration, profitability, electricity system management, and emissions reduction. CLAP can be used to query wind energy resource parameters in any selected region, analyze the potential exploitable energy capacity and inform economic assessments of wind power both on land and offshore. CLAP can also provide information about meteorological disasters, real-time monitoring, and prediction for supporting safe operation and maintenance of wind farms. CLAP has been used by several large wind energy companies, such as Goldwind Sci and Tech Co., Ltd.; Seaborne Wind Power Co., Ltd.; and Zhongche Wind Power Company. For example, Seaborne Wind Power Co., Ltd., used CLAP to reduce the development time and cost of Baxianjiao wind power in Rudong County, Jiangsu Province (Zhang 2017).

\section{e. Climate services for urbanization}

In recent years, the issue of urban climate change has garnered a great deal of attention, and the impacts of global climate change and urbanization will further increase in China (Zhai et al. 2018). Chinese cities are expected to face increasingly serious climate risks, such as urban water logging, large-scale haze, and the urban heat island effect, which threaten the sustainable progress of urbanization in China. The NCC has provided climate services for urban planning, including climate risk assessments and climate change projections for regional coordinated development, such as for the Beijing-Tianjin-Hebei region, Xiongan New Area, and Guangdong-Hong Kong-Macao Greater Bay Area.

Despite the availability of some useful climate services in Chinese cities, far more services are urgently needed. For example, Fang et al. (2015) identified the need for targeted urban climate services for urban 
planning and construction, including designing suitable ventilation in cities, designing suitable drainage systems, and analyzing wind load design standards. The Shanghai Meteorological Bureau has provided climate services for the site selection and construction of the Shanghai Disney Resort. The climatic conditions of the selected site are such that a northwest wind is dominant in winter and a southeast wind is dominant in summer. When planning the layout, the height and density of the buildings were designed to increase from southeast to northwest. Thus, in winter, the impact of the cold northwest wind can be lessened, while in summer, the cool and humid sea breeze from the southeast can be introduced to the resort to stimulate local circulation, promote ventilation, and alleviate the heat island effect. Simultaneously, the facilities with pollution sources were placed as much as possible in relation to the prevailing winds with the lowest pollution to reduce the impact on the resort.

Climate services have also been used in constructing sponge cities, especially in the planning and design of urban drainage. An accurate measure of urban rainstorm intensity is the basis for understanding the discharge capacity of the drainage network and for planning and designing urban drainage systems (Qiu 2015). These measures provide a robust scientific basis and accurate design parameters for municipal construction, water affairs, and planning departments and directly affect the investment budget and reliability of the drainage infrastructure. The NCC and provincial climate centers have provided values of rainstorm intensity for major cities in China, which provides support for the safe operation of cities.

\section{f. Climate services for major engineering projects}

The construction and safe operation of major engineering projects, along with the analysis and evaluation of large-scale planning, rely on information related to climate suitability, risk, and possible impact on local climate. For instance, the NCC has provided a range of climate services for the construction and operation of the Three Gorges Project on the Yangtze River. Before construction began, the NCC conducted a thorough study on the possible climate and environmental problems and produced a report on the environmental impact of the Three Gorges Water Conservancy Project on the Yangtze River. During the construction of the project, the climate services focus was on helping to ensure that the construction was completed successfully and safely. Once completed, the climate services focus was placed on how to realize the benefits of flood protection and water resource utilization. In recent years, floods and droughts have occurred frequently in the upper and middle reaches of the Yangtze River basin. Meteorological departments in the river basin regularly provide predictions of precipitation during the critical periods for water storage, water supply, low water levels, and flood seasons. Through a user network, meteorological departments distribute predictions to the dispatching communication center of the Three Gorges Dam. Furthermore, in view of the impact of the Three Gorges Project on local climate, the NCC has also carried out a climate effect assessment on the Three Gorges Project after construction (Jiao et al. 2013). Progress in the development of this climate service now continues in close collaboration with users at the Three Gorges Reservoir, enabling the evaluation and codevelopment of improved products and services to support more robust decision-making toward flood control and energy provision (Bett et al. 2018; Golding et al. 2019).

The NCC has long engaged in permafrost observations for the construction and safe operation of the Qinghai-Tibet Railway. Research on how global warming impacts the melting of permafrost along the railway has been conducted, and projections have been proposed. To address this issue, railway authorities have taken various measures when designing the project, which have ensured its safe operation for more than a decade $(\mathrm{Wu}$ and Niu 2013).

\section{Summary}

The primary means of evaluating the benefits of CFCS is user feedback and satisfaction. The conference for climate service users is held by the NCC every year to solicit such feedback, and the feedback has been that $88 \%$ of users felt satisfied from 2017 to 2019 . The climate services are also assessed by the social and economic benefits that they have brought to users. This is a far more difficult metric of success to define and measure, but studies in 2011 suggested that the annual economic benefit of weather and climate services for multiple sectors in China was estimated to be around 279.3 billion Chinese yuan, contributing about $1 \%$ to Chinese GDP (Yao et al. 2011; T. Zhang et al. 2011). Another indicator is the contribution to scientific progress, namely, how the interactions and services have facilitated a deeper understanding of climate mechanisms and the advancement of climate science and applied technologies. During the past five years, 816 papers have been published in journals of varying tiers to the benefit of the scientific community in terms of China National Knowledge Infrastructure (CNKI).

The development and implementation of climate services under the CFCS in China has provided extensive experience and lessons that have worldwide relevance. In 
particular, we highlight the following key aspects of climate services.

\section{a. The transition of climate research to operational climate services}

The pull-through of climate research to operational climate services is fundamental for the CFCS. It enables research developments to be influenced, and perhaps even coproduced, between users and researchers. It is a positive way to improve climate service ability and usefulness. For example, research within China's Climate Science for Service Partnership (CSSP) project has enabled understanding of the impacts of current and future climate variabilities and extremes on crops (Kent et al. 2017, 2019). The progress in research on this topic is providing key evidence to support long-term agricultural planning and cropping structure adjustment in China (Belcher et al. 2018). CSSP China has also been engaging users and scientists through developing prototype climate services that pull-through climate research for potential use in operational climate services at a later date (Hewitt and Golding 2018).

The development of climate services highlights the need for skill in climate predictions on multiple scales and in the seamless provision of climate predictions over the course of a month, a season, and a year to cover climate elements, important weather processes, extreme weather and climate events, meteorological disasters, and climatic phenomena. Significant efforts to develop climate prediction models and statistical prediction methods within the operational services and research community in China mean that the accuracy of climate predictions at subseasonal to seasonal time scales in 2011-15 is 5\% higher on average than that in 2001-10 (Zheng et al. 2019), which provides strong support for decision-making on disaster prevention and reduction. Continued pull-through of scientific advances and the reflection of user needs back to the science community is greatly needed to ensure the continued quality and relevance of climate services.

\section{b. Delivering relevant, tailored, and usable climate information}

Relevant, tailored, and usable climate information can support society in developing better management of risks and opportunities related to climate. CMA has established a risk-based early warning system from which the benefits are being demonstrated through practical experiences worldwide (Jiao et al. 2015). After years of development, the NCC has also established a climate impact assessment service including comprehensive climate risk assessment indicators; quantitative assessment of the scope, intensity, duration, and losses in meteorological disasters; and assessment of the impacts of climate variability and climate change in forestry, water resources, health, transportation, environment, and energy. These services are tailored to decision-making needs to allow companies to form research reports and investment proposals based on the above information and for the effective management of disasters for society. The NCC also applied visualization techniques such as CLAP to help users interpret and utilize climate information as effectively and efficiently as possible. Continued efforts to develop more focused and tailored climate services, along with increased levels of evaluation, are needed to ensure that climate services remain relevant and usable by decision-makers.

\section{c. Effective engagement between users and providers of climate services}

The climate service user interface platform is the means to ensure that climate services are developed and delivered successfully. Effective climate services must bridge the gap between climate service providers and information users with appropriate engagement between the providers and users (Golding et al. 2017a,b; Hewitt et al. 2017). The interface can provide users with timely climate information and help them to use this information for robust decision-making and by collecting feedback, requirements, and recommendations, climate services targeting can be improved. The interface covers different user groups and encourages interaction among users, user representatives, service providers, and researchers. Users and expert teams of suppliers are gathered together through regional climate outlook forums (Daly and Dessai 2018), departmental collaborations, expert research groups, and networking. Furthermore, the coproduction of climate information and knowledge with users can increase its usability and better meet user needs (Wall et al. 2017; Briley et al. 2015; Bisbal 2018). Recent user engagement activities in China demonstrate that the coproduction of the knowledge model is very useful to build trust between scientific and user communities (Kruk et al. 2017).

\section{d. Building a professional interdisciplinary team}

Building interdisciplinary teams of climate scientists, social scientists, researchers, forecasters, and communication specialists can bridge and narrow the gaps between providers and users in all stages of climate services development (Christel et al. 2018). The NCC has organized such a team of 15 professionals in its Climate Application Branch (CAB), including experts 
in climate science; specialists in impact, adaptation, and vulnerability; social managers; and communication specialists. The CAB identifies user requirements, gathers feedback, communicates with a range of stakeholders, and bridges any gaps in the climate service development and delivery chain, all to support decisionmakers. The $\mathrm{CAB}$ focuses on stakeholders in water resources, agriculture, energy, urbanization, and major engineering projects and has significantly increased the number of climate services and users in the NCC. The $\mathrm{CAB}$ has enhanced the climate awareness of users and the reputation of the NCC as well as stimulated the progress of NCC operations and research driven by societal needs (Zheng et al. 2019).

\section{Concluding remarks}

Despite the successes evident in the examples presented here, there are also challenges and some failures that afford useful lessons to be learned from climate service practices. The first is the skill of climate predictions, the level of detail available in the predictions and inherent uncertainty in the predictions. As an example, in 2019, the precipitation across the middle and lower reaches of the Yangtze River was predicted to have a fairly high probability of being higher than average and hence a prediction was made for flooding, but it turned out that the rainy season in that region ended early without as much rain as was predicted. Taking the Hubei Province as an example, no heavy rains occurred after 22 June. However, since it had drained its reservoirs on the basis of the climate prediction, the water storage was inadequate for agricultural irrigation during the autumn drought.

The second challenge or failure has been insufficient use of climate information in decision-making. The challenge arises both in terms of climate service providers not making their information accessible, useful, and valuable enough for the decision-makers or the decision-makers not being aware of the value or relevance of climate information in their decision-making. Climate is often a relatively minor part of the decisionmaking process, but in some cases the climate may be more relevant than the decision-makers realizes. For instance, Kunming's new airport is located east of Kunming within the range of the Yunnan-Guizhou quasi-stationary front, which will result in frequent foggy, rainy, and cloudy days during spring and winter. The Yunnan Climate Center put forward this issue when the location selection was in process, but the civil aviation authority eventually chose to put the airport in Changshui, a city east of Kunming, after taking various factors into consideration. As a result, this new airport is constantly subjected to heavy fog (Zhang 2019).
Therefore, climate service capability and delivery in China suffer from several shortcomings and challenges, of which three key shortcomings are identified here in more detail.

First, climate service capability cannot meet the current needs of decision-makers, and this gap is growing. Part of this is because climate services are not always able to use the latest advances in climate science or have insufficient spatial and temporal resolutions, reliability, and accuracy of information for meeting user requirements. Currently, the uncertainties in extended-range outlooks are substantial and sometimes fail to support users in promptly taking measures to prepare for meteorological hazards (Song et al. 2013). The availability of climate change information in risk assessment and risk management required by end users or the communication of climate change information between providers and users is still a problem. For example, there is a large gap between climate prediction and climate change projection capability and demand at the level of prediction accuracy, climate change uncertainty, and impact-based climate prediction and projection, particularly for extreme events. Providers of climate services should aim to improve their communication skills, improve the quality of their services and their delivery chain, enhance awareness among user communities of the existence and usefulness of their climate services, and use new and innovative technologies and methods to generate information that is based on an understanding of user requirements.

Second, many decision-makers in climate-sensitive sectors have an insufficient awareness of their vulnerability to future climate change (Brasseur and Gallardo 2016). Limited or no understanding of climate change by decision-makers reflects the crucial need to improve climate change communication between climate service providers and users (Moser 2016). Decision-makers would benefit from having a better understanding of climate-related hazards and impacts as well as climate change risks. Robust, high-resolution regional climate change scenarios are needed along with quantification of the impacts and risks (Sutton 2019). A more comprehensive assessment of the risk of meteorological disasters associated with climate variability and climate change needs to be undertaken, along with an analysis of the vulnerability of the hazard-affected system and interactions among meteorological-related disasters and socioeconomic systems.

Third, interactions between users and providers should be more proactive to improve the understanding of decision points and what climate services may be useful and usable (Lemos et al. 2012). The ability for providers to offer usable climate information and for users to make 
good use of climate information needs to be improved, and training in the use of climate information for decision-making should be strengthened. A key part of this task is the improved evaluation of climate services and closer interaction between providers and users to coproduce products and improve services (Golding et al. 2017b; Wall et al. 2017). The development and delivery of climate services in China, if not worldwide, requires significant interaction among providers, researchers, and users of climate services. These interactions must involve decision-makers, policy makers, local users, climate scientists, and sectoral experts.

The development, delivery, and uptake of high-quality, relevant, usable, and effective climate services will facilitate climate-smart decisions that will reduce climate risks and improve Chinese societal resilience. Real-time risk monitoring, improved accuracy of predictions, effective risk-based early warning, improved access and uptake of climate services, and greater innovations will make climate services more valuable and usable. There is a need to develop and strengthen the capacity of end users to more effectively access and apply climate services. In turn, climate service developers need to be agile and innovative in responding to changing and emerging social needs, integrating climate information and climate resilience into all walks of life so that everyone can benefit from climate services for economic and social gain. Part of this agility and innovation can be provided by the next generation of information and communication technologies, as we see in the evolutions of mobile phones, internet, and digital broadcast media. Consultancy services and personalized services will enable users greater and improved access to climate services. As an example, automatically adapted climate service products could be developed, leading to greater efficiency, reduced costs, and faster development cycles, all of which can ensure that climate services can improve decision-making for social and economic benefits, drawing on and further developing scientific knowledge and capability in China and worldwide.

In conclusion, in this paper, we have described the successful design and implementation of the CFCS and have introduced a range of examples of the services provided, as well as their societal benefits. The combined experiences of providing such a range of climate services allow us to reflect on the associated challenges, which include a growing gap between climate science and services capability and the societal need for such services, a lack of awareness in user communities of the value of climate services to their activities, and the important need for closer and more meaningful interactions between users and providers of climate services. We highlight that some areas needed for improvement have relevance beyond the Chinese context: the need for a more sustained pull-through of science development to climate services to make use of the latest advances, the need to tailor climate services to specific user needs, ways in which we can improve effective engagement between users and providers of climate services, and the need to develop strong interdisciplinary teams for the development and provision of climate services. We also consider the potential benefits that climate services may bring to a future, climate-resilient society, supported by the areas of improvement highlighted and further enhanced by an increased level of agility and innovation in this field, all of which contributes to the potential ability of climate services to improve resilience to climate-related risks in China and worldwide.

Acknowledgments. This work was jointly supported by the National Key R\&D Program of China (Grant 2018YFA0606302) and the U.K.-China Research and Innovation Partnership Fund through the Met Office CSSP China as part of the Newton Fund. We thank the editor and three anonymous reviewers who all made very valuable suggestions for improvement of this paper.

\section{REFERENCES}

Asrar, G. R., V. Ryabinin, and V. Detemmerman, 2012: Climate science and services: Providing climate information for adaptation, sustainable development and risk management. Curr. Opin. Environ. Sustainability, 4, 88-100, https://doi.org/ 10.1016/j.cosust.2012.01.003.

Belcher, S., E. Stott, L. Song, Q. Chao, R. Lu, and T. Zhou, 2018: Preface to special issue on Climate Science for Service Partnership China. Adv. Atmos. Sci., 35, 897-898, https:// doi.org/10.1007/s00376-018-8002-0.

Bett, P. E., and Coauthors, 2018: Seasonal forecasts of the summer 2016 Yangtze River basin rainfall. Adv. Atmos. Sci., 35, 918-926, https://doi.org/10.1007/s00376-018-7210-y.

Bisbal, G. A., 2018: Practical tips to establish an actionable science portfolio for climate adaptation. Sci. Public Policy, 46, 148-153, https://doi.org/10.1093/scipol/scy070.

Brasseur, G. P., and L. Gallardo, 2016: Climate services: Lessons learned and future prospects. Earth's Future, 4, 79-89, https:// doi.org/10.1002/2015EF000338.

Briley, L., D. Brown, and S. E. Kalafatis, 2015: Overcoming barriers during the co-production of climate information for decision-making. Climate Risk Manage., 9, 41-49, https://doi.org/ 10.1016/j.crm.2015.04.004.

Burke, C., and P. A. Stott, 2017: Impact of anthropogenic climate change on the East Asian summer monsoon. J. Climate, 30, 5205-5220, https://doi.org/10.1175/JCLI-D-16-0892.1.

Chan, F. K. S., J. A. Griffiths, D. Higgitt, S. Xu, F. Zhu, Y. Tang, Y. Xu, and C. R. Thorne, 2018: "Sponge City" in China-A breakthrough of planning and flood risk management in the urban context. Land Use Policy, 76, 772-778, https://doi.org/ 10.1016/j.landusepol.2018.03.005.

Chen, Y., and Coauthors, 2019: Anthropogenic warming has substantially increased the likelihood of July 2017-like heat 
waves over central eastern China. Bull. Amer. Meteor. Soc., 100, S91-S95, https://doi.org/10.1175/BAMS-D-18-0087.1.

Cheng, J., S. Li, and Q. Wu, 2006: Consideration on the water management in China. China Popul. Resour. Environ., 16, 162-168, https://doi.org/10.3969/j.issn.1002-2104.2006.06.031.

Christel, I., D. Hemment, D. Bojovic, F. Cucchietti, L. Calvo, M. Stefaner, and C. Buontempo, 2018: Introducing design in the development of effective climate services. Climate Serv., 9, 111-121, https://doi.org/10.1016/j.cliser.2017.06.002.

CMA, 2015: China Climate Bulletin. China Meteorological Administration, $50 \mathrm{pp}$.

_ 2017: Annual Statement of Meteorological Disaster in China (2016). China Meteorological Press, 222 pp.

Daly, M., and S. Dessai, 2018: Examining the goals of the regional climate outlook forums: What role for user engagement? Wea. Climate Soc., 10, 693-708, https://doi.org/ 10.1175/WCAS-D-18-0015.1.

Dong, B., R. T. Sutton, W. Chen, X. Liu, R. Lu, and Y. Sun, 2016: Abrupt summer warming and changes in temperature extremes over northeast Asia since the mid-1990s: Drivers and physical processes. Adv. Atmos. Sci., 33, 1005-1023, https:// doi.org/10.1007/s00376-016-5247-3.

Fang, J., J. Zhu, and Y. Shi, 2018: The responses of ecosystems to global warming. Chinese Sci. Bull., 63, 136-140, https://doi.org/ 10.1360/N972017-00916.

Fang, X., X. Wang, W. Du, L. Li, X. J. He, C. Cheng, and Y. Liu, 2015: The application of climate information in urban planning in China: Retrospect and future prospect. Diqiu Kexue Jinzhan, 30, 445-455, https://doi.org/10.1167/j.issn.10018166.2015.04.0445.

Golding, N., C. P. Hewitt, P. Zhang, P. X. Bett, X. Fang, H. H. Hu, and S. Nobert, 2017a: Improving user engagement and uptake or climate services in China. Climate Serv., 5, 39-45, https:// doi.org/10.1016/j.cliser.2017.03.004.

_ C. Hewitt, and P. Q. Zhang, 2017b: Effective engagement for climate services: Methods in practice in China. Climate Serv., 8, 72-76, https://doi.org/10.1016/j.cliser.2017.11.002.

,,,--- M. Liu, J. Zhang, and P. Bett, 2019: Co-development of a seasonal rainfall forecast service: Supporting flood risk management for the Yangtze River basin. Climate Risk Manage., 23, 43-49, https://doi.org/10.1016/ j.crm.2019.01.002.

Han, Z., Y. Shi, J. Wu, Y. Xu, and B. Zhou, 2019: Combined dynamical and statistical downscaling for high-resolution projections of multiple climate variables in the BeijingTianjin-Hebei Region of China. J. Appl. Meteor. Climatol., 58, 2387-2403, https://doi.org/10.1175/JAMC-D-19-0050.1.

Hawkins, E., and R. Sutton, 2009: The potential to narrow uncertainty in regional climate predictions. Bull. Amer. Meteor. Soc., 90, 1095-1108, https://doi.org/10.1175/2009BAMS2607.1.

Hewitt, C., and N. Golding, 2018: Development and pull-through of climate science to services in China. Adv. Atmos. Sci., 35, 905-908, https://doi.org/10.1007/s00376-018-7255-y.

_ S. Mason, and D. Walland, 2012: The global framework for climate services. Nat. Climate Change, 2, 831-832, https:// doi.org/10.1038/nclimate1745.

— R. Stone, and A. Tait, 2017: Improving the use of climate information in decision-making. Nat. Climate Change, $\mathbf{7}$, 614-616, https://doi.org/10.1038/nclimate3378.

IPCC, 2014: Summary for policymakers. Climate Change 2014: Impacts, Adaptation, and Vulnerability. Part A: Global and Sectoral Aspects, C. B. Field et al., Eds., Cambridge University Press, 1-32.
Jiao, M., and Coauthors, 2013: Addressing the potential climate effects of China's Three Gorges project. WMO Bull., 62, 49-53.

—, L. Song, T. Jiang, D. Zhang, and J. Zhai, 2015: China's implementation of impact and risk-based early warning. WMO Bull., 64, 1-5.

Kent, C., E. Pope, V. Thompson, K. Lewis, A. A. Scaife, and N. Dunstone, 2017: Using climate model simulations to assess the current climate risk to maize production. Environ. Res. Lett., 12, 054012, https://doi.org/10.1088/1748-9326/ aa6cb9.

-, and Coauthors, 2019: Maize drought hazard in the northeast farming region of China: Unprecedented events in the current climate. J. Appl. Meteor. Climatol., 58, 2247-2258, https:// doi.org/10.1175/JAMC-D-19-0096.1.

Kirchhoff, C. J., 2013: Understanding and enhancing climate information use in water management. Climatic Change, 119, 495-509, https://doi.org/10.1007/s10584-013-0703-x.

Kruk, M. C., B. Parker, J. J. Marra, K. Werner, R. Heim, R. Vose, and P. Malsale, 2017: Engaging with users of climate information and the coproduction of knowledge. Wea. Climate Soc., 9, 839-849, https://doi.org/10.1175/WCAS-D-16-0127.1.

Lemos, M. C., C. J. Kirchhoff, and V. Ramprasad, 2012: Narrowing the climate information usability gap. Nat. Climate Change, $\mathbf{2}$, 789-794, https://doi.org/10.1038/nclimate1614.

Li, C., and Coauthors, 2018: Attribution of extreme precipitation in the lower reaches of the Yangtze River during May 2016. Environ. Res. Lett., 13, 014015, https://doi.org/10.1088/17489326/aa9691.

Li, Y., and G. Zhao, 2014: A review of low-carbon city construction research in China. Ecol. Econ., 10, 66-79.

Lourenço, T. C., R. Swart, H. Goosen, and R. Street, 2016: The rise of demand-driven climate services. Nat. Climate Change, $\mathbf{6}$, 13-14, https://doi.org/10.1038/nclimate2836.

Moser, S. C., 2016: Reflections on climate change communication research and practice in the second decade of the 21st century: What more is there to say? Wiley Interdiscip. Rev.: Climate Change, 7, 345-369, https://doi.org/10.1002/wcc.403.

Prokopy, L. S., J. S. Carlton, T. Haigh, M. C. Lemos, A. S. Mase, and M. Widhalm, 2017: Useful to usable: Developing usable climate science for agriculture. Climate Risk Manage., 15, 1-7, https://doi.org/10.1016/j.crm.2016.10.004.

Qin, D., J. Zhang, C. Shan, and L. Song, 2015: China National Assessment Report on Risk Management and Adaptation of Climate Extremes and Disasters. Science Press, 136 pp.

Qiu, B., 2015: The connotation, approach and prospect of Sponge City. Urban Rural Constr., 2, 8-16, https://doi.org/10.3880./ j.issn.1004-6933.

Song, L., F. Xiao, and W. Li, 2013: The current status and future development of modern climate operation in China. Yingyong Qixiang Xuebao, 24, 513-520, https://doi.org/CNKI:SUN: YYQX.0.2013-05-001.

Sun, Y., L. Song, H. Yin, X. Zhang, P. Stott, B. Zhao, and T. Hu, 2016: Human influence on the 2015 extreme high temperature events in western China. Bull. Amer. Meteor. Soc., 97, S102-S106, https://doi.org/10.1175/BAMS-D-16-0158.1.

Sutton, R. T., 2019: Climate science needs to take risk assessment much more seriously. Bull. Amer. Meteor. Soc., 100, 1637-1642, https://doi.org/10.1175/BAMS-D-18-0280.1.

Tonya, H., and Coauthors, 2018: Provision of climate services for agriculture: Public and private pathways to farm decisionmaking. Bull. Amer. Meteor. Soc., 99, 1781-1790, https:// doi.org/10.1175/BAMS-D-17-0253.1. 
UNFCCC, 2015: The Paris Agreement. United Nations Framework Convention on Climate Change, https://unfccc.int/paris_ agreement/items/9485.php.

Vaughan, C., S. Dessai, and C. Hewitt, 2018: Surveying climate services: What can we learn from a bird's-eye view? Wea. Climate Soc., 10, 373-395, https://doi.org/10.1175/WCASD-17-0030.1.

Wall, T. U., A. M. Meadow, and A. Horganic, 2017: Developing evaluation indicators to improve the process of coproducing usable climate science. Wea. Climate Soc., 9, 95-107, https:// doi.org/10.1175/WCAS-D-16-0008.1.

Wang, J., S. Tett, Z. Yan, and J. Feng, 2018: Have human activities changed the frequencies of absolute extreme temperatures in eastern China? Environ. Res. Lett., 13, 014012, https://doi.org/ 10.1088/1748-9326/aa9404.

Wang, Y., B. Zhou, Y. Ren, and C. Sun, 2016: Impacts of global climate change on China's climate security. Yingyong Qixiang Xuebao, 27, 750-758.

- and Coauthors, 2018: Construction and application of a climate risk index for China. J. Meteor. Res., 32, 937-949, https:// doi.org/10.1007/s13351-019-8106-1.

Weichselgartner, J., and B. Artheimer, 2019: Evolving climate services into knowledge-action systems. Wea. Climate Soc., 11, 385-399, https://doi.org/10.1175/WCAS-D-18-0087.1.

$\mathrm{Wu}$, Q., and F. Niu, 2013: Permafrost changes and engineering stability in Qinghai-Xizang Plateau. Chinese Sci. Bull., 58, 1079-1094, https://doi.org/10.1007/s11434-012-5587-z.

Xiao, F. H., C. Zhang, B. Wang, H. Wang, C. Liu, and A. Wang, 2006: Impact of climatic change on agriculture and its adaptation countermeasures in China. Ziran Zaihai Xuebao, 15, 327-331.

Xie, X., and Y. Zheng, 2017: Research on the evaluation indicator system for climate adaptive cities: A case study of Beijing.
Chinese J. Urban Environ. Stud., 5, 1750007, https://doi.org/ 10.1142/S2345748117500075.

Yao, X., M. Liu, X. Fan, J. Wang, and L. Wang, 2011: Review on evaluation of meteorological service benefits. Meteor. Mon., 37, 749-755.

Zhai, J., Y. Liu, P. Hou, T. Xiao, and G. Cao, 2016: Water conservation service assessment and its spatiotemporal features in National Key Ecological Function Zones. Adv. Meteor., 2016, 5194091, https://doi.org/10.1155/2016/5194091.

Zhai, P., Y. Yuan, R. Rong and J. Guo, 2018: Climate change and sustainable development for cities. Chinese Sci. Bull., 64 1995-2001, https//doi.org/10.1360/N972018-00911.

Zhang, T., S. Song, C. Tian, X. Chai, and S. Pan, 2011: The benefit valuation method and analytical study of profession meteorological service in China. J. Meteor. Sci., 31, 194-199, https:// doi.org/10.3969/2012JMS.00.

Zhang, W., H. Li, and X. An, 2011: Ecological civilization construction is the fundamental way to develop low-carbon economy. Energy Procedia, 5, 839-843, https://doi.org/10.1016/ j.egypro.2011.03.148.

Zhang, X., 2019: Analysis of the climatic characteristics at Kunming Changshui airport. Adv. Meteor. Sci. Technol., 9, 41-45.

Zhang, Z., 2017: Huaneng Rudong Offshore Project explores the path for the application of domestic $5 \mathrm{MW}$ wind turbines, and offshore wind power accelerates into the era of large units. China Energy News, http://www.sohu.com/a/ 198387678_468637.

Zheng, G., M. Jiao, Y. Ding, and L. Song, 2019: China Climate. China Meteorological Press, 318 pp.

Zhou, F., D. Zou, 2016: The core concepts, main points and basic rules of ecological economy. Hunan Nongye Daxue Xuebao, 17, 100-102, https//doi.org/10.13331/j.cnki.jhau(ss).2016.01.017. 